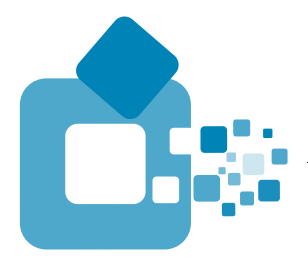

\title{
Beyaz Zeminde Sunulan Farklı Renkteki Kelimelerin Lise 10̈ğrencilerinin Anlık ve Kısa Süreli Bellek Performansları Üzerine Etkisi
}

Effect of Different Color Words Presented on White Background on High School 1st Grade Students' Instant and Short-Term Memory Performance

\section{Münire Ece YAMAN ${ }^{1^{*}}$}

${ }^{1}$ Yusuf Ziya Öner Fen Lisesi, Antalya / Türkiye ${ }^{1}$ Yusuf Ziya Öner Science High School, Antalya / Türkiye *eceyaman07@yahoo.com.tr

${ }^{1}$ ORCID: 0000-0002-6402-6694

\section{Emin KUTLU}

${ }^{2}$ Yusuf Ziya Öner Fen Lisesi, Antalya / Türkiye ${ }^{2}$ Yusuf Ziya Öner Science High School, Antalya / Türkiye

${ }^{2}$ ORCID: 0000-0002-9638-6934

\section{MAKALE BILLGISİ / ARTICLE INFORMATION \\ Geliş Tarihi / Date Received \\ 07.03.2019 \\ Yayın Tarihi / Date Published \\ Aralık / December 2019 \\ Kabul Tarihi / Date Accepted \\ 17.12.2019 \\ Yayın Sezonu / Pub Date Season \\ Aralık-Haziran / December - June}

\section{ATIF / CITE as}

Yaman, M. E. ve Kutlu, E. (2019). “Beyaz Zeminde Sunulan Farklı Renkteki Kelimelerin Lise 1 Öğrencilerinin Anlık ve Kısa Süreli Bellek Performansları Üzerine Etkisi” / "Effect of Different Color Words Presented on White Background on High School 1st Grade Students' Instant and Short-Term Memory Performance”. bilar: Bilim Armonisi Dergisi, 2 (2): $35-$ 43. doi: 10.37215/bilar.2019257647

\section{https://dergipark.org.tr/tr/pub/bilar}

Copyright @ Published by Antalya İl Millî Eğitim Müdürlüğü Since 2018, Antalya, 07100 Turkey. All rights reserved. 


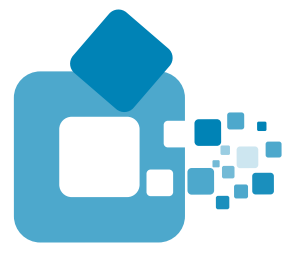

Beyaz Zeminde Sunulan Farklı Renkteki Kelimelerin Lise 10̈ğrencilerinin Anlık ve Kısa Süreli Bellek Performansları Üzerine Etkisi

Effect of Different Color Words Presented on White Background on High School 1st Grade Students' Instant and Short-Term Memory Performance

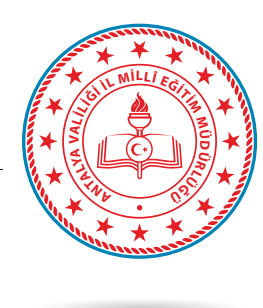

\section{ÖZET}

İnsan yaşamında renklerin önemli yeri bulunmaktadır. Renkler toplumsal hayatı düzenlemek için de kullanılır. Bu çalışmada farklı renklerde yazılmış kelimeler kullanılarak, renklerin belleğe olan etkisinin incelenmesi amaçlanmıştır. Çalışmaya 9. Sınıf öğrencileri dâhil edilmiştir. Öğrencilere ders başlamadan önce / Testin ilk bellek bölümü ve dersin bitimine doğru yarım saat sonra da testin ikinci bölümü uygulanmıştır. Uygulama formu kişisel bilgilerin alındığı soru formu, İshihara Testi ve bellek testinden oluşmaktadır. Bellek testi kısmı için (Öktem'in Sözel bellek süreçleri testi 10 kelime belirlenmiştir (Bahçe, Ayakkab1, At, Kamyon, Limon, Bardak, Cami, Ekmek, Yıldız ve Sabah). Renk olarak da kırmızı, sarı, mavi ve siyah renk seçilmiştir. Beş öğrenciye pilot uygulama yapılmış ve toplamda ortalama 14 (12-16 dakika) dakikada uygulanmıştır. Bellek testlerinin iç tutarlığı yüksek bulunmuştur (Cronbach alfa=0.93, $\mathrm{N}=5)$. Anlamlılık düzeyi olarak p<0.05 belirlenmiştir. Çalışmaya kırk altısı $(\% 41,8)$ kadın ve $64(\% 58,2)$ 'ü erkek olmak üzere toplamda 110 kişi katılmıştır. 5. A (Kırmızı), B (Mavi), C (Sarı) ve D (Siyah) grupları aralarındaki bellek puanları arasındaki fark incelediğinde 1. Testte renk grupları arasında anlamlı farkın olmadığ1 ve diğer test ölçümlerde anlamlı fark olduğu anlaşılmıştır $(p<0.01)$. Anlık bellek 3 . Testte kırmızı ve siyah daha kalıcı olmuştur $(\mathrm{p}<0.001)$. 4. Testte kırmızı renk 5. Testte tek başına diğer renk gruplarına göre daha yüksek bellek puanlarına sahip olmuştur $(p<0.01)$. Kırmızı renk tek başına diğer renk gruplarına üstün gelmiştir $(\mathrm{p}<0.01)$. Tüm grupların süreç içerisindeki bellek puanındaki değişim anlamlı olduğunu göstermişlerdir $(p<0.01)$. Bütün gruplarda bellek testlerinin ölçümün yapıldığı zaman ilerledikçe kırmızı renkli test haricinde süreç içerisindeki bellek puanının azaldığı bulunmuştur $(p<0.01)$. Bu çalışmada elde edilen sonuçlar, beyaz zemin üzerinde sunulan kırmızı ve siyah renkli kelimelerin hafızada daha fazla kalıcı olduğunu göstermekte, bu da kontrast içeren renk kombinasyonlarının daha dikkat çekici, dolayısıyla belleğe daha olumlu etkisi olduğunu düşündürmektedir.

Anahtar Sözcükler: Renk, bellek, akılda tutma, eğitim, öğrenme.

\section{ABSTRACT}

Colors are very important in human life. Colors are also used to regulate social life. The purpose of this study is to examine the effect of colors on memory by using words written in different colors. 9th grade students were included in the study. The first memory part of the test was applied to the students before the course and the second part of the test was applied half an hour later to the end of the lesson. The questionnaire consists of personal information, Ishihara Test result and memory test sections. Ten words were determined randomly (Öktem's Verbal Memory Process Test) (Garden, Shoe, Horse, Truck, Lemon, Cup, Mosque, Bread, Star and Morning). In the color selection, red, yellow, blue and black were taken. Five students were piloted and applied on a total of 14 (12-16 minutes) minutes. The internal consistency of memory tests $w$ as found to be high (Cronbach alpha $=0.93, \mathrm{~N}=5$ ). The significance level was set at $(\mathrm{p}$ $<0.05)$. 110 people participated in the study. Forty-six $(41.8 \%)$ were female and $64(58.2 \%)$ were men 110 people participated in the study. When the difference between the A (Red), B (Blue), C (Yellow) and D (Black) groups were examined, it was found that there was no difference between the color groups in the 1 st Test and there was a significant difference in the other test measurements $(\mathrm{p}<0.01)$. 3. Instant memory red and black were more permanent in the test $(\mathrm{p}<0.01)$. 4. In the test, the red color alone had higher memory scores than the other color groups $(p<0.01)$. 5. In the test the red color was superior to other color groups $(p<0.01)$. All groups showed significant change in the memory score in the process $(p<0.01)$. The memory score of each group in the process, red color test, except for the other color memory tests were observed to decrease as the time progressed $(p<0.01)$. The results obtained in this study show that the red and black words presented on the white background are more permanent in memory, suggesting that color combinations containing contrast are more remarkable and therefore have a more positive effect on memory.

Keywords: Color, memory, mind keeping, education, learning. 


\section{Gíriş}

Renkler hayatımızın çok önemli bir kısmında görev almaktadır (Bae, G. Y., Olkkonen, M., Allred, S. R. ve Flombaum, J. I. 2015 ). Teknolojik çağda yaşayan bizler her gün, her saat, her dakika, her saniye gerek televizyonda, gerek telefonda, hemen hemen her yerde renkleri kullanır ve anlamlandırırız. Renkler toplumsal hayatı düzenlemek için de kullanılır. (Trafikte kullanılan uyarılar, işaretler, trafik lambaları vb.). Ayrıca renkler, iletişim, reklamc1l1k, hatta spor, rehabilitasyon gibi alanlarda yoğun olarak kullanılır (Bae, G. Y., Olkkonen, M., Allred, S. R., ve Flombaum, J. I. 2015). Çevremizde gördüğümüz her nesneyi algilama, öğrenme ve hafıamıza kaydetmemizde renklerin önemli bir etkisi vardır (Witzel ve Gegenfurther 2013).

Bellek, bilgilerin kayıt edilmesi, muhafaza edilmesi ve gerektiğinde geri çağırılarak kullanılmasını içeren bir zihinsel süreçtir (Özenici 2009). Dikkat ise, çevremizde var olan pek çok bilgi arasından bazılarını seçerek kullanmamızı sağlayan bir diğer zihinsel süreçtir. Bellek ve dikkat birlikte, öğrenmenin temelini oluşturur (Marchetti 2014). Dolayısıyla, renklerin bellek, dikkat ve öğrenme üzerine olan etkisi pek çok araştırmacının ilgisini çekmiştir (Olurinola ve Tayo 2015). Beyaz zeminde ve kontrastın daha belirgin olduğu renk kombinasyonlarıyla sunulan bilgilerin daha çabuk okunduğu ve daha dikkat çekici olduğu görülmüştür (Dzulkifli ve Mustafar 2013).

Renkli sunumların insanlarda uyarılma sağladı̆̆ ve bir miktar uyarının da bellek ve öğrenme üzerine olumlu etkisinin olabileceği düşünülmektedir. Sarı ve kırmızı gibi sıcak renklerin, mavi ve yeşil gibi soğuk renklere göre daha fazla dikkat çekici ve uyarıcı etkisi olduğu öne sürülmüştür (Grass ve Seiter 2018). Sıra dişı, uyarıcı ve dikkat çeken uyarımlar beyinde hormonal değişimlere sebep olarak öğrenme düzeyini ve bellek kapasitesini arttırabilir (Sandi ve Pinelo-Nava 2007). Huchendorf'un (2007) çalışmasında, öğrencilere sicak, soğuk renkler ve beyaz zeminli sayfalarda verilen kelimelerin, hangi grupta, bellekte daha çok kaldığ 1 araştırılmış ancak gruplar arasında anlamlı bir farklılık bulunamamıştır.

Okuduğumuz ve yazdı̆̆ımız metinlerde genelde punto rengi olarak siyah rengi kullanılır. "Siyah renk yerine farkl1 renkler kullanılsayd1 nasıl değişimler olurdu ve acaba bu değişimler hangi yönde gerçekleşirdi?" gibi sorular araştırma alanında ilgi ve merak konusu olmuştur.

Bu çalışmada farklı renklerde yazılmış kelimeler kullanılarak, renklerin hafızaya olan etkisinin incelenmesi amaçlanmaktadır. Renklerin belleğe olan etkisinden bahsederken sadece tek türlü belleğe değil, hem kısa hem de uzun süreli bellekte oluşan etkilerden bahsedilmektedir. Düz beyaz zemin üzerinde farklı renkler kullanılarak öğrencideki öğrenme, bilgilerin belleğe işlenmesi bakımından farklılık var mıdır sorusuna da yanıt aranmıştır.

\section{MATERYAL VE METOT}

\subsection{Katilımcilar}

Çalışmaya Yusuf Ziya Fen Lisesinin 2018-2019 eğitim öğretim yılında öğrenim gören 9. sınıfta kayıtlı olan öğrenciler dâhil edilmiştir. Çalışmaya ilişkin formlar 2018 yılının Aralık ayında bir hafta zarfında, öğrencilerin ders saatlerinde uygulanmıştır. Derse başlamadan önce anket setinin ilk aşaması, yarım saat sonrasında ise anket setinin ikinci aşaması uygulanmıştır. Anket uygulanmadan önce katılımcılara çalışmanın amacı, hedefi, uygulanışı ve olası zararları açıklanmıştır. Katılımın gönüllülük esaslı olduğu vurgulanmıştır. Ayrıca katılımcılara aydınlatılmış onam formu yazılı olarak da verilmiş ve gönüllü katılmak istediklerine dair onamları alınmıştır.

Çalışmamızda 116 öğrenciye ulaşılmıştır. Bir öğrenci katılmak istememiş ve beş öğrenci renkli görmeyi test eden Ishihara Renk Testini (Ishihara Color Test 2015) geçemedikleri için çalışmaya alınmamışlardır.

\subsection{Veri Toplama Aracı}

Çalışmanın konusu renklerin belleğe etkisi olduğu için bellek performansını test etmek için bir yöntem aranmıştır. Bu amaçla bir Anket/Test hazırlan mıştır.

Anket kişisel bilgileri (ad-soyad, yaş, sınıfı, yatılı kalıp kalmadığı, memleketi, kullandı̆̆ 1 eli), İshihara Testi sonucunu ve bellek test kısımlarından oluşmaktadır. Bellek testi bölümü için günlük hayatta sıkça kullanılan birbiriyle ilişkisiz, çağrışım yapmayan 10 kelime rasgele belirlenmiştir. Kelimeler Öktem'in Sözel bellek süreçleri testi (SBST)'inden seçilmiştir (Öktem 1992). Belirlenen kelimelerin dört farklı anket/ testte dört farklı gruba uygulanmasına karar verilmiştir. Bu dört farklı anket/test grubu ise dört farklı renkte aynı on kelimeyi içermekte idi. Anketler A,B,C ve D olmak üzere dört gruba ayrılmıştır ve gruplara sırasıyla kırmızı, mavi, sarı ve siyah renklerde kelimeleri içeren anketler verilmiştir. Her biri beyaz A4 sayfasına yukarıdan aşağıya ve soldan sağa ortalayarak, kalibri (gövde) karakteriyle, koyu ve 36 font ebadiyla yazılar yazılmıştır. Seçilen kelimeler Bahçe, Ayakkabı, At, Kamyon, Limon, Bardak, Cami, Ekmek, Yildiz ve Sabah olmuştur. Renk seçiminde ise renklerin özellikleri belirleyici olmuştur. Kırmızı, sarı ve mavi renkler 
ana renklerdir. Siyah ise nötr renktir. Ayrıca kırmızı ve sarı sıcak renk, mavi ise soğuk renktir. Yani bu çalışmada sıcak, soğuk ve nötr renkler arasındaki farklılıklar incelenmek istenmiştir (Color Theory n.d.). Anket/Testin hafıza ile ilgili kısmının dört aşamada uygulanmasına karar verilmiştir. Birinci aşamada 10 kelimenin katılımcı tarafından iki dakika içinde incelenmesine izin verilmiş ve ardından liste alınmışve hatırladı̆̆ Sonra dikkatini dağıtmak için iki dakika içinde bir matematik sorusu sorulmuş ve yanıtlanması istenmiştir. Matematik problemine ilişkin sonuçlar dikkate alınmamış, sadece katılımcının dikkatini dağıtmak amacıyla kullanılmıştır. Matematik probleminden sonra 10 kelimeyi hatırlaması ve dağıtılan forma yazmaları istenmiştir. Bu kısımla ilgili Anket/Test formları yeniden toplanmıştır ve anketörler sınıftan ayrılmıştır. İkinci uygulama ise 30 dakika sonra yapılmıştır. Test formuna 10 kelimeyi hatırlayıp, yazmaları istenmiştir. Formlar toplandiktan sonra kendilerine bu kez 30 kelime içeren bir Anket/Test formu dağıtıp, kendilerine ders başında gösterilen 10 kelimeyi bu kelimeler içinden hatırlayıp, işaretlemeleri istenmiştir. Otuz kelime yine Öktem'in Sözel bellek süreçleri testi (SBST)'inin önerileri doğrultusunda hazırlanmıştır (Öktem 1992).

Bellek puanları ise her bir bellek testinde doğru olarak yazılan/seçilen kelimelerin toplam sayısından elde edilmiştir. 5. Testte ise 30 kelimeden seçilen 10 kelimeden her bir fazlasına birer puanlık ceza puanı uygulanmıştır. Yani normalde 10 kelime işaretlemesi gerekirken 12 kelime işaretlendiği takdirde 2 ceza puanı uygulanmış ve doğru bilinen kelimelerden 2 puan kesilmiştir.

\subsection{Veri Toplama}

Anket lise 1. sınıf olan yaşları 14 ve 15 arasında değişen öğrencilere uygulanmıştır. Anketi uygulamadan önce kendilerine bilgilendirici birtakım formlar dağıtılmış, incelemeleri isten miştir ve katılmak istediklerine dair onamları içeren imzaları alınmıştır. Onam formunda çalışmanın amacı açıklanmıştır. Arzu ettiklerinde çalışmadan çekilebilecekleri ifade edilmiştir. Katılmak istemeyen bir öğrenci çalışmaya alınmamıştır. Beş öğrenciye pilot uygulama yapılmıştır. Son değişiklikleri ile ölçüm araçları hedef kitleye uygulanmıştır.

Anket/Test renk algısın1 kapsadı̆̆ 1 için katılımcıların hepsinin uygulama öncesi Ishiara Kartları ile renkli görmeleri test edilmiştir (Ishihara Color Test, 2018). Bu anketin değerlendirilmesine diskromotopsisi (renk körü) olan öğrenciler $(N=5)$ dahil edilmemiştir. Anket/Test Yusuf Ziya Öner Fen Lisesi 9. sınıf öğrencilerinden oluşan dört sınıf üzerinden yapılmıştır. Araştırmaya konu olan dört farklı renk grubu rasgele biçimde her bir sınıfa kura yöntemi ile atanmıştır. Çalışma çift kör biçimde uygulanmıştır. Anketi uygulayanlar katılımcıların ve katılımciların kendilerinin hangi grupta olduklarını bilmemekteydi. 9/A sınıfına D (Siyah), 9/B sinıfina A (Kırmızı), 9/C sinıfına B (Mavi) ve 9/D sınıfına ise C (Sarı) Anket/Testi uygulanmıştır.

Anket/Testi kişisel bilgilerin toplanması ve Ishiara testinden sonra bellek beş aşama olarak gerçekleştirilmiştir. Test bekleme süresi hariç toplamda Ort= $14 \mathrm{dk}$ sürmüştür.

Bellek testlerinin iç tutarlığı (Cronbach alfa $=0.925, \mathrm{n}=5$ ) bulunmuştur.

\subsection{Verilerin İşlenmesi ve Analizi}

$\mathrm{Bu}$ çalışmada elde edilen veriler özelliklerine göre işlenmiştir. Tanımlayıcı istatistik kullanılmıştır. Bellek testlerinin renk gruplarına göre ortalamalarının farklarının değerlendirilmesi için eşleştirilmemiş tek yönlü varyans analizi uygulanmıştır. Gruplar arasında varyansların homojen olması, gruplarda bulunan katılımc1 sayılarının eşit olmaması ve verilerin interval niteliği taşımaları nedeniyle post-hoc test olarak Duncan testi tercih edilmiştir. Katılımcıların süre içindeki hafıza değişimi için ise eşlemiş tek yönlü varyans analizi uygulanmıştır. Mauchly'nin Sferite Testi ve Greenhouse-Geisser Testi ve ardından alt grup analizinde iki eş arasındaki farkın anlamlılık testi uygulanmıştır. Anlamlılık düzeyi $\mathrm{p}<0.05$ olarak Kabul edilmiştir.

\section{BULGULAR}

$\mathrm{Bu}$ çalışmaya 110 kişi dâhil edilmiştir. Yaşları ortalama 14.35 (SS=0.481; min-maks=14-15)'tır. $46(\% 41.8)^{\prime}$ sı kadın ve $64(\% 58.2)^{\prime}$ ü erkektir. 93 $(\% 84.5)^{\prime} \ddot{u}$ sağ elini, 9(\%8.2)'u sol elini ve $8(\% 7.3)^{\prime} \mathrm{i}$ her iki elini kullanmaktadır. 73'ü evde kalıyorken (\%66.4), 37'si yurtta (\%33.6) kalmaktadir. Katılımcıların çoğu Antalya merkez ( $=79$; \%71.8), bir kısmı Antalya'nın ilçelerinden $(\mathrm{N}=25$; \%22.7) ve azı Antalya ili dışından $(\mathrm{N}=6 ; \% 5.5)$ gelmektedir.

Bellek testlerinde elde edilen sonuçlar Çizelge 1 'de gösterilmiştir. 


\begin{tabular}{|c|c|c|c|c|c|c|c|}
\hline & $\begin{array}{c}\mathbf{N} \\
\text { Geçerli Veri }\end{array}$ & Eksik Veri & Ortalama & Medyan & $\begin{array}{l}\text { Standart } \\
\text { Sapma }\end{array}$ & Minumum & Maksimum \\
\hline Yaşı & 110 & 0 & 14,35 & 14,00 & 0,48 & 14 & 15 \\
\hline $\begin{array}{l}\text { 1. Test: "Az önce verdiğimiz kelimeler hangileriydi?" } \\
\text { sorusuna verilen doğru yanıtların sayısı: }\end{array}$ & 110 & 0 & 9,80 & 10,00 & 0,57 & 7 & 10 \\
\hline $\begin{array}{l}\text { 3. Test:" Az önce verdiğimiz kelimeler hangileriydi?" } \\
\text { sorusuna verilen doğru yanıtların sayısı: }\end{array}$ & 110 & 0 & 9,62 & 10,00 & 0,81 & 5 & 10 \\
\hline $\begin{array}{l}\text { 4. Test: "Yarım saat önce verdiğimiz kelimeler hangileriydi?" } \\
\text { sorusuna verilen doğru yanıtların sayısı: }\end{array}$ & 110 & 0 & 9,08 & 9,50 & 1,13 & 5 & 10 \\
\hline $\begin{array}{l}\text { 5. Test: "Size gösterilen listedeki kelimeler bunlardan hangileriydi?" } \\
\text { sorusuna verilen doğru yanıtların sayısı: }\end{array}$ & 110 & 0 & 8,97 & 9,50 & 1,27 & 5 & 10 \\
\hline
\end{tabular}

A (Kırmızı), B (Mavi), C (Sarı) ve D (Siyah) renk grupları arasında anlamlı farkın olmadı̆̆ı grupları aralarındaki bellek puanları arasındaki ve diğer test ölçümlerde anlamlı fark olduğu fark incelediğinde (Çizelge 2 ve Şekil 1) 1. Testte belirlenmiştir

\begin{tabular}{|c|c|c|c|c|c|c|}
\hline & & $\begin{array}{l}\text { Kareler } \\
\text { Toplam }\end{array}$ & df & $\begin{array}{l}\text { Kareler } \\
\text { Ortalama }\end{array}$ & $\mathbf{F}$ & $\mathbf{p}$ \\
\hline \multirow{3}{*}{$\begin{array}{l}\text { 1. Test: "Az önce verdiğimiz kelimeler hangileriydi?" } \\
\text { sorusuna verilen doğru yanıtların sayısı: }\end{array}$} & Guplar Arası & 2,03 & 3 & 0,68 & 2,13 & 0,10 \\
\hline & Guplar İçi & 33,57 & 106 & 0,32 & & \\
\hline & Toplam & 35,60 & 109 & & & \\
\hline \multirow{3}{*}{$\begin{array}{l}\text { 3. Test:" Az önce verdiğimiz kelimeler hangileriydi?" } \\
\text { sorusuna verilen doğru yanıtların sayısı: }\end{array}$} & Guplar Arası & 7,52 & 3 & 2,51 & 4,12 & 0,01 \\
\hline & Guplar İ çi & 64,45 & 106 & 0,61 & & \\
\hline & Toplam & 71,96 & 109 & & & \\
\hline \multirow{3}{*}{$\begin{array}{l}\text { 4. Test: "Yarım saat önce verdiğimiz kelimeler hangileriydi?" } \\
\text { sorusuna verilen doğru yanıtların sayısı: }\end{array}$} & Guplar Arası & 29,31 & 3 & 9,77 & 9,33 & 0,01 \\
\hline & Guplar i̇çi & 110,96 & 106 & 1,05 & & \\
\hline & Toplam & 140,26 & 109 & & & \\
\hline \multirow{3}{*}{$\begin{array}{l}\text { 5. Test: "Size gösterilen listedeki kelimeler bunlardan hangileriydi?" } \\
\text { sorusuna verilen doğru yanıtların sayısı: }\end{array}$} & Guplar Arası & 38,40 & 3 & 12,80 & 9,79 & 0,01 \\
\hline & Guplar İçi & 138,52 & 106 & 1,31 & & \\
\hline & Toplam & 176,92 & 109 & & & \\
\hline
\end{tabular}

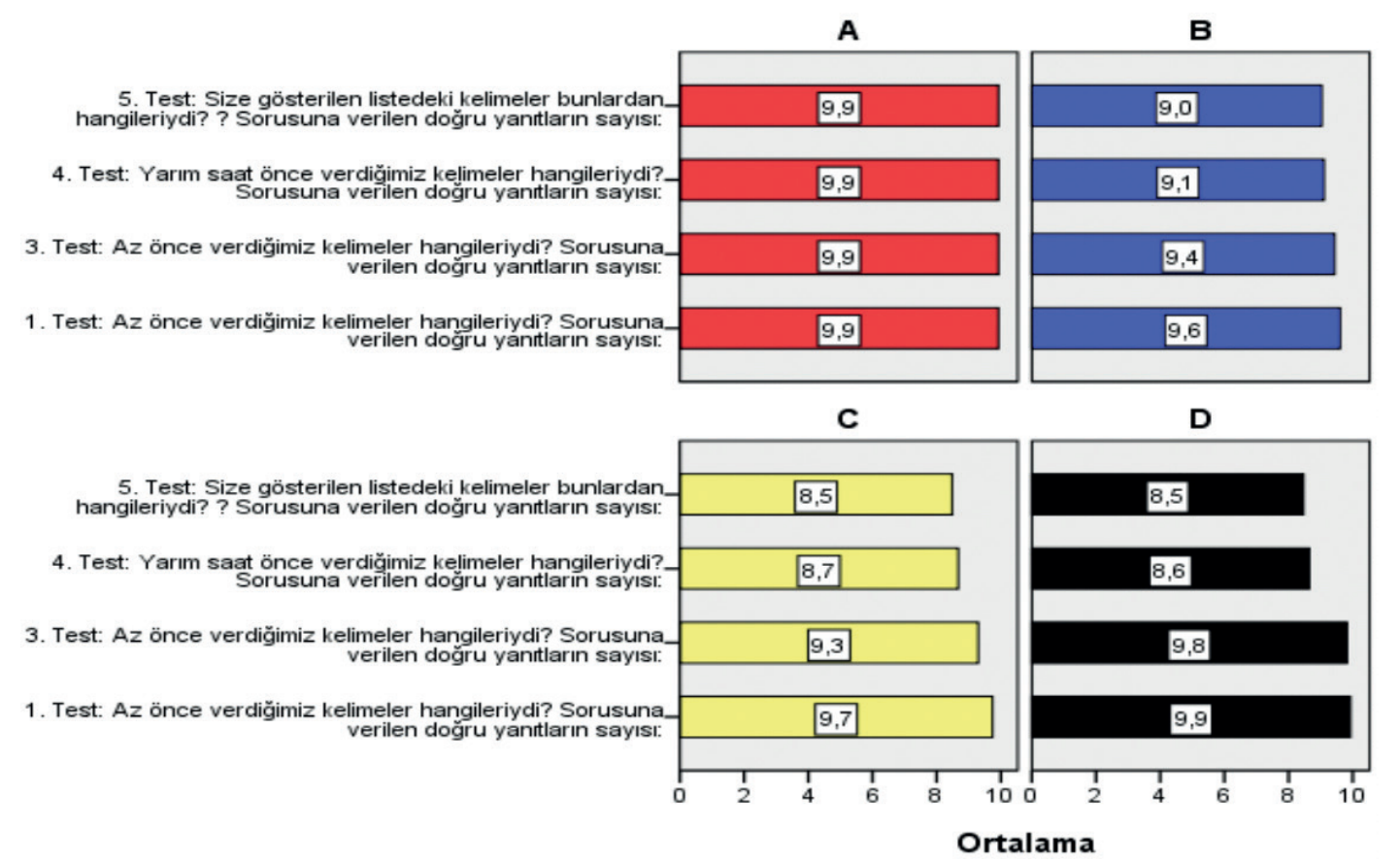

Şekil 1. A (Kırmııı), B (Mavi), C (Sarı) ve D (Siyah) Grupları Aralarındaki Bellek Puanları Arasındaki Fark 
Üçüncü testte farka neden olan renk grupları Çizelge 3'te gösterilmiştir. Buna göre matematik probleminden sonra yapilan testte (3. Test) kirmizi ile siyah renk ile gösterilen kelimelerin hatırlanma oranları arasında fark olmamakla birlikte, diğer iki renge (mavi ve sarı) göre daha yüksek bellek puanları ölçülmüştür. Yani anlık bellekte kırmızı ve siyah daha kalıcı olmuştur.

\begin{tabular}{|c|c|c|c|c|c|}
\hline ANOVA & & & & oha $=0$ & \\
\hline Duncan ${ }^{a . b}$ & Anket Grubu & $\mathbf{N}$ & 1 & 2 & 3 \\
\hline \multirow{5}{*}{$\begin{array}{l}\text { 3. Test:" Az önce verdiğimiz kelimeler hangileriydi?" } \\
\text { sorusuna verilen doğru yanıtların sayısı: }\end{array}$} & C & 27 & 9,30 & & \\
\hline & B & 28 & 9,43 & 9,43 & \\
\hline & D & 28 & & 9,82 & 9,82 \\
\hline & A & 27 & & & 9,93 \\
\hline & Anlamlılık Düzeyi & & 0,53 & 0,07 & 0,620 \\
\hline
\end{tabular}

a. Örneklemin Harmonik Ortalaması $=27,49$

4. Testte farka neden olan renk grupları çizelge 4'te gösterilmiştir. Buna göre 30 dakikalık ders süresinden sonra yapılan testte (4. Test) kırmızı renk tek başına diğer renk gruplarına göre daha yüksek bellek puanlarına sahip olmuştur. Diğer grupların bellek puanları anlamlı olarak daha düşük bulunmuştur.

\begin{tabular}{|c|c|c|c|c|}
\hline ANOVA & & & & \\
\hline Duncan ${ }^{a . b}$ & Anket Grubu & $\mathbf{N}$ & 1 & 2 \\
\hline \multirow{5}{*}{$\begin{array}{l}\text { 4. Test: "Yarım saat önce verdiğimiz kelimeler hangileriydi?" } \\
\text { sorusuna verilen doğru yanıtların sayısı: }\end{array}$} & D & 28 & 8,64 & \\
\hline & C & 27 & 8,67 & \\
\hline & B & 28 & 9,11 & \\
\hline & A & 27 & & 9,93 \\
\hline & Anlamlılık Düzeyi & & 0,12 & 1,00 \\
\hline
\end{tabular}

a. Örneklemin Harmonik Ortalaması

b. Grup büyüklükleri eşit değildir.

5. Testte farka neden olan renk grupları çizelge 5'te gösterilmiştir. Buna göre 30 dakikalık ders süresinden sonra yapılan testin ardından, katılımcıya seçmek üzere verilen 30 kelimenin arasından öğrenilmesi istenen kelimeleri seçtikleri kısa süreli bellek testinde (5. Test) kırmızı renk tek başına diğer renk gruplarına üstün gelmiştir. Diğer renklerin bellek puanları anlamlı olarak daha düşük bulunmuştur.

\begin{tabular}{|c|c|c|c|c|}
\hline \multicolumn{3}{|l|}{ ANOVA } & \multicolumn{2}{|c|}{ alpha $=0,05$} \\
\hline Duncan $^{a . b}$ & Anket Grubu & $\mathbf{N}$ & 1 & 2 \\
\hline \multirow{5}{*}{$\begin{array}{l}\text { 5. Test: "Size gösterilen listedeki kelimeler bunlardan hangileriydi?" } \\
\text { sorusuna verilen doğru yanıtların sayısı: }\end{array}$} & D & 28 & 8,46 & \\
\hline & C & 27 & 8,48 & \\
\hline & B & 28 & 9,04 & \\
\hline & A & 27 & & 9,93 \\
\hline & Anlamlılık Düzeyi & & 0,082 & 1,00 \\
\hline
\end{tabular}

a. Örneklemin Harmonik Ortalaması

b. Grup büyüklükleri eşit değildir.

Tüm grupların süreç içerisindeki bellek puanındaki değişim ise şekil 2'de gösterilmiştir. Mauchly'nin Sferite Testinin h0 hipotezinin reddedilmesi nedeniyle (Mauchly's W $\mathrm{F}(5)=0.14$, $\mathrm{p}=0.01)$ Greenhouse-Geisser Testi $(\mathrm{F}(1,42 ; 154,94)=$
$60,94 ; p=0.01)$ dikkate alınmıştır. Bellek testlerinin eşli karşılaştırmaları her bir bellek testi ölçümleri arasında anlamlı fark olduğunu göstermişlerdir $(\mathrm{p}<0.01)$. 


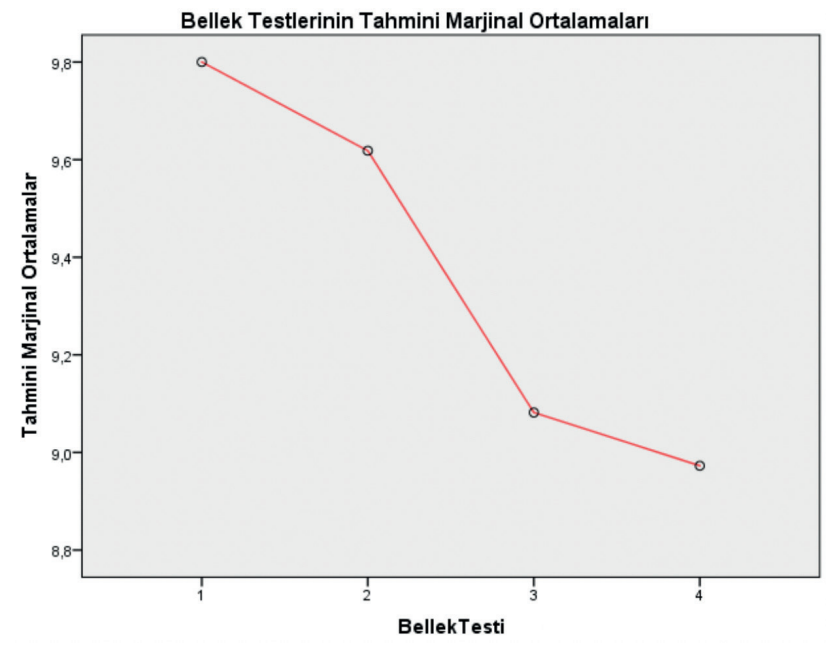

Şekil 2. Tüm Grupların Süreç Içerisindeki Bellek Puanındaki Değişimi

Her bir grubun süreç içerisindeki bellek puanındaki değişim ise şekil 3'te gösterilmiştir. Mauchly'nin Sferite Testinin h0 hipotezinin reddedilmesi nedeniyle (Mauchly's W $\mathrm{F}(5)=0.24$, $\mathrm{p}=0.01) \quad$ Greenhouse-Geisser Testi $\quad(\mathrm{F}(4,80$; $169,65)=15,42 ; p=0.01)$ dikkate alınmıştır. Bellek testlerinin kendi renk grupları içerisindeki eşli karşılaştırmalarında kırmızı renkli test haricinde diğer renkli bellek testlerinin ölçümünün yapıldığg zaman ilerledikçe azaldıkları görülmüştür $(\mathrm{p}<0.01)$ (Şekil 3).

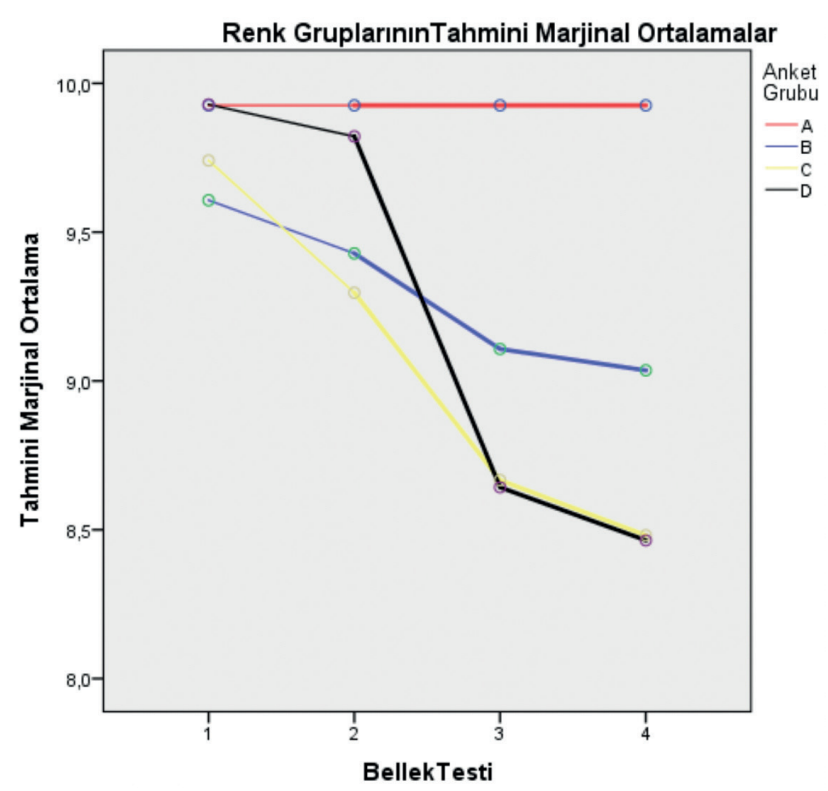

Şekil 3. Dört Farklı Renk Grubunun Zaman İçindeki Bellek Puanlarının Değişimi

\section{SONUÇ VE TARTIŞMA}

$\mathrm{Bu}$ çalışmada lise birinci sınıfında okuyan öğrencilere uygulanan farklı renkteki yazı karakterlerin anlık ve kısa süre etkileri araştırılmıştır. Anlık bellek için iki test uygulanırken, kısa süreli bellek için de iki test uygulanmıştır. İlk testte renklerin bellek üzerine bir etkileri saptanmazken, ikinci testte kırmızı ve siyah rengin daha kalıcı olduğu ve daha sonraki üçüncü ve dördüncü ölçümlerde ise yalnızca kırmızı rengin hafızada daha kalıcı olduğu saptanmıştır.

$\mathrm{Bu}$ çalışmada elde edilen sonuçlar, beyaz zeminde sunulan kırmızı ve siyah renkli kelimelerin bellekte daha fazla kalıcı olduğunu göstermektedir. Bu bulgulardan özellikle beyaz zemin üzerinde siyahın daha iyi bellekte kaldı̆̆ına ilişkin literatür bilgisi mevcuttur (McConnohie BV 1999; Hall RH ve Hanna P 2004). Kırmızı üzeri beyaz gibi yüksek kontrastlı renk kullanımı özellikle reklam alanında kullanılmaktadır. Bu da daha önce yapılan bazı çalışmalar ve öne sürülen hipotezlerle uyumlu bir sonuç olarak yorumlanmıştır (Dzulkifli ve Mustafar 2013; Wichmann, F.A.; Sharpe, L.T. ve Gegenfurtner, K.R. ,2002). Huchendorf'un (2007) çalışmasında sicak renkler, soğuk renkler ve beyaz zeminli sayfalarda yazılı olan bilgiler test edilmiş ve gruplar arasında anlamlı bir fark gözlenmemişti. Biz ise, çalışmamızda daha farklı bir yöntem izleyerek, sabit beyaz zeminde, renkli kelimeler vererek bellek üzerindeki etkisini araştırdık ve kırmızı ve siyah renkler lehine farklılık gözledik. Bu farklılık kırmızıda en belirgin idi. Renk skalasında sıcak renkler (örn. kırmızı, sarı) uyarıcı, soğuk renkler ise (örn. mavi) rahatlatıcı, sakinleştirici olarak tanımlanmaktadır (Huchendorf, L. 2007). Sicak renklerin uyarıcı etkisinin yanı sıra, bazen endişe arttırıcı etkilerinin de olabileceği gözlenmiştir (Singg ve Mull 2017). Renklerin etkisinin eğitim alanında kullanılabileceği ve öğrenmeyi arttırabildiği gösterilmiştir (Olurinola ve Tayo 2015). Ancak hangi renklerin öğrenme üzerine daha etkili olduğu ile ilgili literatürde birbiri ile çelişen çalışmalar mevcuttur (Olurinola ve Tayo 2015; Fear 2016; Wichmann, F.A., Sharpe, L.T. ve Gegenfurtner, K.R. 2002). Çalışmamızda elde edilen, kırmızı renkli kelime/şekillerde görülen daha yüksek hafıza performansı daha önce yapılan bazı çalışmalarda da gösterilmiştir (Krahn 2018). Uyarıcılık, dikkati arttıran bir faktör, artmış dikkat de uzun süreli bellek üzerine olumlu etki gösteren bir faktör olarak gözlenmiştir.

Çalışmamızda elde edilen sonuçlar, sarı ve mavi renklerin daha düşük bellek performansı ile ilişkili bulunmasıydı. Sarı, sicak dolayısıyla uyarıcı bir renk olmasına rağmen, beyaz zemin üzerinde kontrast oluşturmadığı için daha az dikkat çekici olmuş, ve sarı renkle ilişkili bellek puanları daha düşük bulunmuştur. Öte yandan, mavi renk, beyaz zemin üzerinde yeteri kadar kontrast oluşturmasına rağmen soğuk bir renk olmasına bağlı olarak daha az uyarıcı, dolayısıyla daha az dikkat çeken ve kırmızı ve siyaha göre daha düşük hafıza puanlarıyla ilişkili bir renk olduğu düşünülmektedir 
Renklerin dikkat ve bellek üzerindeki, dolayısıyla öğrenme üzerindeki etkileri bazı araştırmacıların dikkatini çekmiş ve bu konuda bazı çalışmalar yapılmış olsa da, çalışmalar yetersizdir (Singg, S., Mull, Ch.W. 2017; Olurinola, O. ve Tayo, O. 2015.) ve renklerle belleğimiz arasındaki ilişkinin tüm yönlerini açıklamaktan henüz uzaktır. Mevcut çalışmada daha önce denenmemiş bir yöntem ve çalışma tasarısı ile bu ilişki açıklanmaya çalışılmıştır. Uyarıcı, sıcak renkler, özellikle kırmızı renk bellek üzerinde olumlu etkilere sahiptir. Uyarıc1lıtan sonra ikinci derecede önemli unsur, yazılı bilginin sunumunda kullanılan kontrast etkisidir. Beyaz zeminde sunulan kırmizı renkte bellek en iyi performansı gösterirken, bunu beyaz zemin üzerinde sunulan siyah renk izlemektedir. Çalışmamız yöntemi ve elde edilen sonuçlarıyla özgün bir nitelik taşımaktadır.

Gelecekte renklerin algı, dikkat, hafıza ve öğrenme ile olan ilişkisini tüm boyutlarıyla anlamak, bu ilişkiyi eğitim alanına uyarlamak ve olumlu etkilerinden faydalanmak için daha fazla sayıda katılımcının olduğu, daha ayrıntılı yönleri inceleyen, daha kapsamlı çalışmalara ihtiyaç vardır.

\section{TEŞEKKÜR}

Bu çalışmamızda yardımlarından dolayı özellikle anketin uygulanması kısmında Yusuf Ziya Öner Fen Lisesi yönetimine teşekkürlerimi sunarım.

\section{KAYNAKLAR}

10 Reasons to Use Color. (31.05.2019). Erişimi: http: / / understanding.com / design/10-reasons-touse-color/

Bae, G., Olkkonen, M., Allred, S.R., ve Flombaum, J.I. (2015). “Why some colors appear more memorable than others: A model combining categories and particulars in color working memory". Journal of experimental psychology. General, (144) 4: 744-63.

Color Theory. (n.d.). Erişim adresi: https:// cios233. community.uaf.edu / design-theory-lectures / colortheory/ Erişim tarihi: 01.12.2018.

Dzulkifli, M.D. ve Mustafar, M.F. (2013). “The Influence of Colour on Memory Performance: A Review". Malays J Med Sci., 20(2), 3-9.

Fear, A. (2016). "The Effects of Color Preference on Word List Recall. Honors Senior Teses/Projects. 92. Erişim adresi: htps://digitalcommons.wou.edu/ honors_theses/92.

Grass, R.H. ve Seiter, J.S. (2018). "Persuasion: Social Influence and Compliance Gaining Routledge, 6th Edition". Erişim adresi: https:// books.google.com.tr/https://books.google.com. $\mathrm{tr} / \mathrm{books}$ ? id=eipKDwA AQBAJ\&pg=PT539\&dq= $\mathrm{W}$ a r m + colors $+1 \mathrm{i} \mathrm{ke}+\mathrm{ye} l 1 \mathrm{ow}+\mathrm{and}+\mathrm{red}$, + Persuasion: + Socia $1+$ Influence + and + Compliance + Gaining \& h l $=$ tr \& s a $=X \&$ v e d $=0$ a h UKE w i J u 7 a s T i A h L x o s KHbSbAIYQ6AEILDAA\# $\mathrm{v}=$ onepage $\& \mathrm{q}=$ Warm $\% 20$ colors $\% 201$ ike $\% 20$ yellow $\% 20$ and $\% 20$ red $\% 2$ C $\% 20$ Persuasion $\% 3$ A $\% 20$ Social $\% 20$ Influence $\% 20$ and $\% 20$ Compliance $\% 20 \mathrm{Gaining} \& \mathrm{f}=$ false
Hall, R. H. ve Hanna, P. (2004). "The impact of web page text-background colour combinations on readability, retention, aesthetics and behavioural intention". Behaviour \& Information Technology, 23(3): 183-195.

Colorpsychology (2019). "How Colors Affect Our Everyday Lives". Erişim tarihi:31.05.2019. Erişim adresi: https://www.colorpsychology.org/howcolors-affect-our-everyday-lives /

Huchendorf, L. (2007). "The effects of color on memory". UW-L Journal of Undergraduate Research, 2007, X, 1-4

Ishihara Color Test. (2015, April 13). Retrieved from https://www.colour-blindness.com/colourblindness-tests / ishihara-colour-test-plates /; Erişim Tarihi: 01.12.2018.

Krahn, E.(2018). “Decomposing the effect of color on memory: How red and blue affect memory differently. Decomposing the effect of color on memory: How red and blue affect memory differently". UndergraduateHonors Teses. 1733. Erişim adresi: htps://scholar. colorado.edu/honr_ theses / 1733

Marchetti G. (2014). “Attention and working memory: two basic mechanisms for constructing temporal experiences". Frontiers in psychology, 5, 880. doi:103389/fpsyg.2014.00880

McConnohie, V, B.(1999) "A Study of the Effect of Color in Memory Retention When Used in Presentation Software. Yayınlanmamış Yüksek Lisans Tezi. Department of Teacher Education, Johnson Bible College. Knoxville, TN, USA. 
Öktem, Ö (1992). "Sözel bellek süreçleri testi (SBST): Bir ön çalışma Nöropsikiyatri Arşivi". 29(4): 196206.

Özenici, S. (2009). “İşleyen Belleğin Okuma Anlama Sürecindeki Rolü ve İşlevi”. Selçuk Üniversitesi Sosyal Bilimler Enstitüsü Dergisi, 22, 467-476.

Olurinola, O. ve Tayo, O. (2015). "Colour in Learning: It's Effect on the Retention Rate of Graduate Students". Journal of Education and Practice, (6)14: 1-6.

Sandi, C. ve Pinelo-Nava, M. T. (2007). "Stress and memory: behavioral effects and neurobiological mechanisms". Neural plasticity, 78970. doi:10.1155/ $2007 / 78970$
Singg, S., Mull, Ch.W. (2017). Effect of Color on Information Retention by Young Men and Women. JOJ Case Stud., 2(4), 555591. DOI:10.19080/ JOJCS.2017.02.55559

Wichmann, F.A., Sharpe, L.T. ve Gegenfurtner, K.R. (2002). "The contributions of color to recognition memory for natural scenes. Journal of experimental psychology Learning". memory, and cognition, 28 (3): 509-20.

Witzel, Ch. ve Gegenfurtner, K. (2013). "Memory Color". Encyclopedia of Color Science and Technology. DOI 10.1007/978-3-642-27851-8_58-8 